\title{
Is it important to examine gender differences in the epidemiology and outcome of severe heart failure?
}

\author{
Mariell Jessup, MDa \\ Ileana L. Piña, $M D^{b}$
}

See related editorials on pages 1245 and 1253.
From the University of Pennsylvania, ${ }^{\text {a }}$ Philadelphia, Pa, and Case Western Reserve University, ${ }^{\mathrm{b}}$ Cleveland, Ohio.

Received for publication July 29, 2003; accepted for publication Sept 9, 2003.

Address for reprints: Mariell Jessup, MD, Heart Failure/Transplant Program, Hospital of the University of Pennsylvania, 6 Penn Tower, 3400 Spruce St, Philadelphia, PA 19104 (E-mail: jessupm@uphs.upenn.edu).

J Thorac Cardiovasc Surg 2004;127:1247-52

$0022-5223 / \$ 30.00$

Copyright () 2004 by The American Association for Thoracic Surgery

doi:10.1016/j.jtcvs.2003.09.032

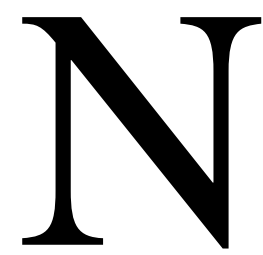

early 5 million Americans have heart failure (HF) today, with an incidence approaching 10 per 1000 population in persons older than 65 years of age; approximately $50 \%$ of these patients are women (Figure 1). ${ }^{1}$ In 2000, 62.3\% of all HF mortalities occurred among women; $20 \%$ of those patients died within 1 year of their diagnosis, and less than $15 \%$ of women survive more than 8 to 12 years after diagnosis. ${ }^{2}$ These results notwithstanding, the Framingham study recently noted that the age-adjusted rates of $\mathrm{HF}$ are higher among men, with no significant change in this rate over a 50-year period. ${ }^{3}$ Among women, the incidence of $\mathrm{HF}$ has decreased by $31 \%$ to $40 \%$ in the decades after 1950 .

$\mathrm{HF}$ is the reason for at least $20 \%$ of all hospital admissions in persons older than 65 years, and over the past decade, hospitalizations for HF have increased by $159 \%$. Women who have been hospitalized with HF have less improvement in physical health status and perceive their quality of care to be lower than that of their male cohorts. ${ }^{4}$ Of the thousands of patients disabled from HF within 6 years of their diagnosis, $46 \%$ are adult women compared with only $22 \%$ of men. In 1997, an estimated $\$ 5501$ was spent for every hospital-discharge diagnosis of HF, and another $\$ 1742$ per month was required to care for each patient after discharge. Gender has been shown to be an important determinant of hospital length of stay, hospital charges, and mortality during hospitalization. ${ }^{5}$

The above statistics and countless other graphs, studies, and reports chronicle 2 very important issues: (1) the syndrome of HF has reached epidemic proportions in the United States and throughout the world, and (2) the disease appears to have different characteristics in men and women. It is reasonable to postulate that an elucidation of these sex-specific differences might suggest novel approaches to the prevention of this serious disorder. Moreover, additional insights into genderspecific pathophysiologic mechanisms that lead to HF might be used to develop unique therapies for this relentlessly lethal disease. This review, then, should be regarded as more than a politically expedient exercise but as one part of the larger battle to fight the syndrome of $\mathrm{HF}$ in all its forms. We would also like to acknowledge the newer literature on this subject since the outstanding review of Petrie and colleagues ${ }^{6}$ was published in 1999.

\section{Epidemiology}

Elderly patients in the United States represent an increasing proportion of patients with HF. There is the general aging of the population, a progressive increase in the age of onset of HF, and improved treatment of other cardiovascular diseases, such as hypertension and myocardial infarction, to account for these figures. ${ }^{7}$ Although the overall prevalence of HF is similar in men and women, there is a striking effect of age on the prevalence of the disease. Men have a much higher prevalence of HF when younger than 75 years of age, whereas women surpass the male prevalence when older than 75 years of age. Importantly, these elderly female patients are much more likely to have HF with preserved systolic function, ${ }^{8-11}$ or "diastolic heart failure," than their younger cohorts. ${ }^{7,12}$

Over the past 50 years, the incidence of HF has decreased among women but not among men. ${ }^{3}$ What could account for this differing gender trend? Treatment of 

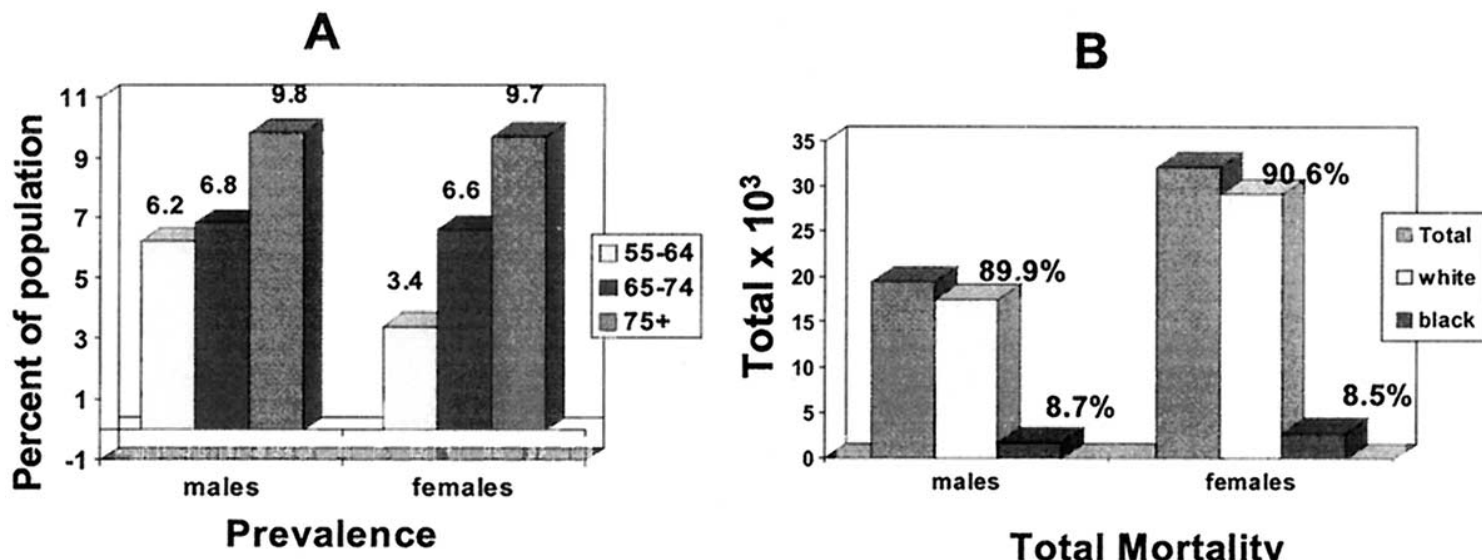

\section{Total Mortality}

Figure 1. Prevalence and mortality of heart failure by gender: A, prevalence of heart failure in the United States, 1988 through 1994, by age group and gender; B, mortality (51,546 total deaths, including Hispanics) in 2000. Percentage of male deaths was $37.6 \%$, and percentage of female deaths was $62.4 \%{ }^{1}$

hypertension reduces the incidence of HF by about $50 \%$, and important advances have occurred in the awareness, treatment, and control of high blood pressure during this time period. ${ }^{13,14}$ The risk of HF imparted by hypertension is greater for women than for men: the population-attributable risk effect of hypertension was 59\% in women and only $39 \%$ in men in an earlier Framingham report. ${ }^{15}$ Increasing use of antihypertensive medications has led to a decrease in the prevalence of high blood pressure and might have affected the incidence of HF in women more so than in men. In men the greater incidence of HF is partly explained by the greater prevalence and incidence of arteriosclerosis and coronary artery disease. Some data also suggest a sex difference in the cardiac response to increased afterload or hypertension, as discussed subsequently.

Ventricular arrhythmias are thought to be caused by a dispersion of normal conduction through nonhomogeneous myocardial tissue, promoting repetitive ventricular rhythms. The rate of sudden cardiac death among persons with HF is 6 to 9 times that seen in the general population ${ }^{16}$ and is more common in men than in women. ${ }^{17}$ One study suggested that women who present with sudden cardiac death are less likely to have a prior history of heart disease than men $(37 \%$ vs $56 \%$ ). More recent data revealed that women with cardiac arrest are less likely than men to have ventricular fibrillation as an initial rhythm. ${ }^{18}$ Albert and colleagues ${ }^{19}$ prospectively followed a cohort of 121,701 women aged 30 to 55 years at baseline and identified 244 cases of sudden cardiac death between 1976 and 1998. Although the risk of sudden death increased markedly as the women grew older, the percentage of cardiac deaths that were sudden decreased with age. Most (69\%) women who had a sudden cardiac death had no history of cardiac disease before their death, but almost all (94\%) of the women who died reported at least 1 coronary risk factor. Smoking, hypertension, and diabetes conferred a significantly increased risk of sudden death similar to that seen in men.

\section{Mortality From Heart Failure}

There has been considerable scrutiny of a possible survival advantage of women once they have HF in contrast to men. Two large epidemiologic studies, Framingham ${ }^{20}$ and NHANES- $1,{ }^{21}$ both reported an improved survival for women, despite a greater average age in the female cohorts. In contrast, the SOLVD investigators noted a worse outlook, with a 1-year mortality rate of $22 \%$ in the women and a $17 \%$ rate in the men of the study. ${ }^{22}$ All patients in SOLVD had a formal measurement of left ventricular ejection fraction (LVEF); entry into the large epidemiologic studies was on the basis of symptoms without an assessment of LVEF. Thus it is probable that the women followed in the earlier studies had a higher incidence of diastolic HF as compared with that in SOLVD, and this might account for their survival advantage. Data from the Italian Network CHF Registry, in which patients were enrolled on the basis of signs and symptoms, reported a similar 1-year mortality in men and women. ${ }^{23}$ However, the women of the cohort were significantly older, had a worse functional class, and exhibited a higher heart rate and systolic blood pressure with more atrial fibrillation but less ventricular tachycardia. In this study women were more likely to have preserved left ventricular (LV) function than men.

It appears that the underlying cause of $\mathrm{HF}$ in women in general is different than that in men, and these baseline risk factors, outside the development of HF, might have an important effect on prognosis. Diabetes, for example, is a stronger risk factor for HF in women than in men, especially in younger women. ${ }^{24}$ In a Framingham report increased 


\section{Gender-related survival rates: a theory}

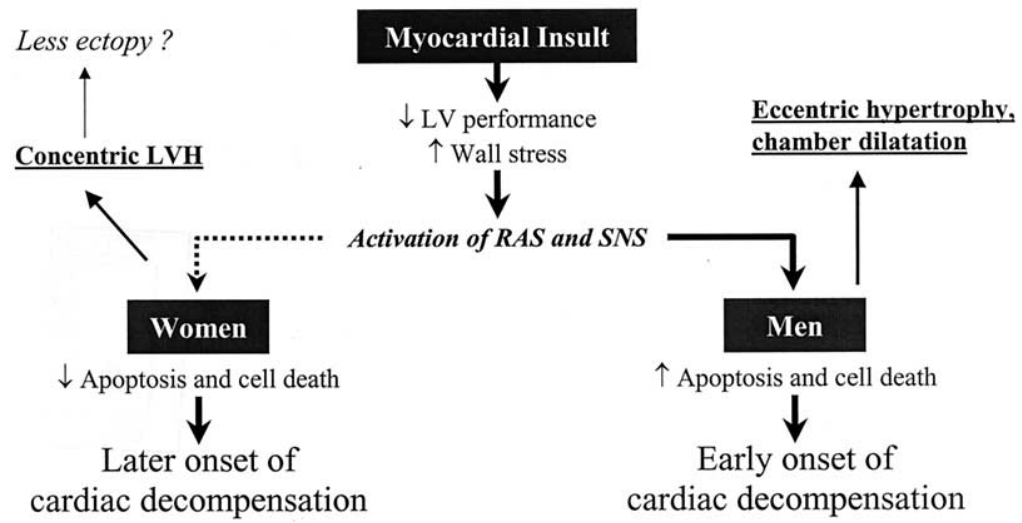

Figure 2. Gender-related survival rates and how they might be influenced by different pathophysiologic mechanisms in men and women. $L V$, Left ventricle; $L V H$, left ventricular hypertrophy; $R A S$, renin-angiotensin system; $S N S$, sympathetic nervous system.

wall thickness and LV mass were found in women but not in men with diabetes mellitus. ${ }^{25}$ Moreover, LV mass and wall thickness increases with worsening glucose intolerance, an effect that is also more striking in women. ${ }^{26}$ Thus if one were to examine a given population of patients with $\mathrm{HF}$, the women in the group would more likely be older, have diabetes, and have hypertension. Age, hypertension, and diabetes are powerful determinants of prognosis in other cardiovascular disorders, such as in patients after myocardial infarction or cardiac surgery, and women frequently do less well because of these additional risk factors. Why is it that women with the same comorbid conditions and HF fare better than their male counterparts?

Mortality outcomes become even more muddled as the large randomized clinical trials are examined with regard to this issue. As mentioned earlier, women survived less frequently in SOLVD, a study of patients with LV systolic dysfunction. ${ }^{22}$ In the FIRST study, which involved patients with far-advanced systolic dysfunction and refractory symptoms, only women without ischemic heart disease had a better prognosis compared with the prognosis of the male patients. ${ }^{27}$ However, in 2 large trials studying patients with systolic dysfunction and symptomatic HF, MERIT-HF ${ }^{28}$ and CIBIS-II, ${ }^{29}$ women had a significantly improved survival, even after adjustment for baseline differences, including $\beta$-blocker treatment and ischemic cause. The mechanisms that determine an enhanced survival for women with HF require elucidation.

\section{Pathophysiology}

Numerous studies have shown that the clinical manifestations and prognosis of women with ischemic heart disease differ significantly from those of men. In spite of having
TABLE 1. Female participants in heart failure trials of left ventricular systolic dysfunction

\begin{tabular}{|c|c|c|c|}
\hline Study & $\begin{array}{c}\text { No. of } \\
\text { patients }\end{array}$ & $\begin{array}{c}\text { No. of } \\
\text { women }\end{array}$ & $\begin{array}{c}\text { Percentage } \\
\text { of women }\end{array}$ \\
\hline CONSENSUS-|39 & 253 & 75 & 30 \\
\hline SOLVD-T40 & 2569 & 504 & 23 \\
\hline SOLVD-P41 & 4228 & 476 & 31 \\
\hline ELITE-| 42 & 722 & 240 & 31 \\
\hline ELITE-II43 & 3152 & 966 & 30 \\
\hline MERIT-HF44 & 3991 & 451 & 23 \\
\hline CIBIS II 45 & 2647 & 515 & 20 \\
\hline COPERNICUS ${ }^{46}$ & 2287 & 465 & 28 \\
\hline $\mathrm{BEST}^{47}$ & 2708 & 593 & 22 \\
\hline Val HEFT48 & 5010 & 1002 & 20 \\
\hline RALES $^{49}$ & 1663 & 446 & 27 \\
\hline SAVE50 & 2231 & 390 & 28 \\
\hline TRACE51 & 1749 & 501 & 22 \\
\hline CHARM 52 & 7599 & 243 & 32 \\
\hline SCD HeFT53 & 2521 & 580 & 23 \\
\hline $\mathrm{DIG}^{54}$ & 6800 & 1520 & 22.4 \\
\hline TOTAL & 50,130 & 11,500 & 23 \\
\hline
\end{tabular}

preserved LV systolic function more often than men, women have more symptoms of HF. ${ }^{30-32}$ Mendes and colleagues $^{33}$ sought to understand more completely the relationship between sex and LV pressure and volume in patients referred for cardiac catheterization. Women comprised 35\% of the 1667 patients undergoing catheterization. They also had a higher prevalence of hypertension ( $41 \%$ in women and $31 \%$ in men), diabetes ( $18 \%$ in women and $12 \%$ in men), and HF (13\% in women and $10 \%$ in men). At the time of the procedure, women had a higher LVEF, $61 \%$ compared with the men's $56 \%$, but had less 3-vessel 
TABLE 2. Differences in heart failure: Women compared with men

\begin{tabular}{|c|c|c|c|c|c|}
\hline & SOLVD22 & FIRST $^{27}$ & MERIT'28 & CIBIS-II29 & Heart failure clinic ${ }^{61}$ \\
\hline $\mathrm{N}$ (\% women) & $6271(26)$ & $471(24)$ & $898(22.5)$ & 2647 (19) & $557(32 \%)$ \\
\hline Age & Older & Older & Older & Older & Younger \\
\hline Ischemia & Less & Less & Less & Less & Less \\
\hline $\mathrm{EF}$ & Same & Same & Same & Same & Higher \\
\hline Diabetes & More & Same & More & More & More \\
\hline Hypertension & More & More & More & More & More \\
\hline $\mathrm{HR}$ & Higher & Higher & Higher & Same & - \\
\hline Race & $\uparrow A A$ & $\uparrow A A$ & - & - & $\uparrow \mathrm{AA}$ \\
\hline Mortality & Higher & Lower in IDC & Lower & Lower in non-IDC & Lower in non-IDC \\
\hline
\end{tabular}

$E F$, Ejection fraction; $H R$, heart rate; $A A$, African American; $I D C$, idiopathic dilated cardiomyopathy.

coronary disease. In a multivariate analysis female sex remained an independent predictor of HF. The LV enddiastolic volume index was smaller in women despite a similar LV end-diastolic pressure. When patients were stratified according to LV end-diastolic pressure, women had a significantly smaller end-diastolic volume. The authors suggested that the response of the left ventricle to the pressureoverload state, such as that seen in hypertension, might be modified by sex. The pressure-volume relationship noted in the study by Mendes and colleagues ${ }^{33}$ accounts for the diastolic abnormalities seen so often in women with HF and explains the degree of symptoms despite a preserved LVEF.

Other pathophysiologic differences exist in patients with HF that appear to be sex determined. Aronson and Burger ${ }^{34}$ examined heart rate variability in patients with nonischemic $\mathrm{HF}$ and found that women have attenuated sympathetic activation and an attenuated parasympathetic withdrawal. Current understanding about the critical role of the sympathetic nervous system in the progression of HF suggests that the above findings might be advantageous. Likewise, investigators have shown that myocyte necrosis and apoptosis are significantly reduced in women with $\mathrm{HF}$, despite a longer duration of disease compared with that seen in the men in the study populations. ${ }^{35}$ There are also considerable data to conclude that gender and sex hormones affect the components of the renin-angiotensin system through a number of mechanisms. ${ }^{36}$

Figure 2 depicts a possible schema of the pathophysiologic response to myocardial injury in men and women derived in part from the above and other studies. The clinical observation that women present with symptoms of HF later in life with more concentric LV hypertrophy might be explained by a gender-specific tendency that confers an improved survival in many instances. Recent reports suggest that the gender response to postinfarction injury favors women in that they have less hypertrophy, a pattern quite different than that observed in nonischemic cardiomyopathy. ${ }^{37}$

\section{Management of Heart Failure}

Our ability to discern whether women respond to pharmacotherapy for HF in a meaningfully dissimilar manner from men has been impaired by the failure to enroll adequate numbers of women into many of the HF trials, as shown in Table $1 .{ }^{38-54}$ To be fair, this low enrollment rate is probably caused, in part, by a greater proportion of diastolic HF in women, making them ineligible for the trials outlined in Table $1 .^{55}$

Women might receive less optimal care for a variety of reasons. Harjai and coworkers ${ }^{56}$ showed that, even after adjusting for age, race, coronary artery disease, and LVEF, there was a higher use of combination therapy by cardiologists in male versus female patients. Improvements in peak exercise capacity might be more pronounced in men than in women with HF after exercise training, and yet women are referred less often to cardiac rehabilitation. ${ }^{57}$ In addition, the skeletal muscle abnormalities described in the legs of male patients with $\mathrm{HF}$ are not as pronounced in women. ${ }^{58}$ Women had more side effects in the SOLVD trial. ${ }^{59}$ Most important, however, is the lack of definitive randomized trials in patients with diastolic HF, a group of patients who are predominantly women. ${ }^{60}$ Some of the differences between men and women at baseline when enrolled in clinical trials are shown in Table 2. 22,27-29,61 Note the greater degree of hypertension and diabetes in women. ${ }^{22,27-29,61,62}$

In summary, there is mounting evidence that there are important sex differences in the phenotype of $\mathrm{HF}$ as we understand it currently. Women appear to have an overall improved outlook once they become symptomatic with HF. The mechanisms behind this advantage are worthy of further exploration.

\section{References}

1. American Heart Association. Heart disease and stroke statistics2003. Dallas, Tex: American Heart Association; 2002.

2. American Heart Association. 2001 Heart disease and stroke statistical update. Dallas, Tex: American Heart Association; 2000.

3. Levy D, Kenchaiah S, Larson MG, et al. Long-term trends in the incidence of and survival with heart failure. N Engl J Med. 2002;347: 1397-402.

4. Chin MH, Goldman L. Gender differences in 1-year survival and quality of life among patients admitted with congestive heart failure. Med Care. 1998;36:1033-46.

5. Philbin EF, DiSalvo TG. Influence of race and gender on care process, 
resource use, and outcomes in congestive heart failure. Am J Cardiol. 1998;82:76-81.

6. Petrie MC, Dawson NF, Murdoch DR, Davie AP, McMurray JJV. Failure of women's hearts. Circulation. 1999;99:2334-41.

7. Gottdiener JS, Arnold AM, Aurigemma GP, et al. Predictors of congestive heart failure in the elderly: the Cardiovascular Health Study. J Am Coll Cardiol. 2000;35:1628-37.

8. Redfield MM, Jacobsen SJ, Burnett JC Jr, Mahoney DW, Bailey KR, Rodeheffer RJ. Burden of systolic and diastolic ventricular dysfunction in the community: appreciating the scope of the heart failure epidemic. JAMA. 2003;289:194-202.

9. Vasan R, Levy D. Defining diastolic heart failure. A call for standardized diagnostic criteria. Circulation. 2000;101:2118-21.

10. Zile MR, Brutsaert DL. New concepts in diastolic dysfunction and diastolic heart failure: part II: causal mechanisms and treatment. Circulation. 2002;105:1503-8.

11. Zile MR, Brutsaert DL. New concepts in diastolic dysfunction and diastolic heart failure: part I: diagnosis, prognosis, and measurements of diastolic function. Circulation. 2002;105:1387-93.

12. Masoudi FA, Havranek EP, Smith G, et al. Gender, age, and heart failure with preserved left ventricular systolic function. J Am Coll Cardiol. 2003;41:217-23.

13. Dahlof B, Lindholm LH, Hansson L, Schersten B, Ekbom T, Wester PO. Morbidity and mortality in the Swedish Trial in Old Patients with Hypertension (STOP-Hypertension). Lancet. 1991;338:1281-5.

14. SHEP Cooperative Research Group. Prevention of stroke by antihypertensive drug treatment in older persons with isolated systolic hypertension. Final results of the Systolic Hypertension in the Elderly Program (SHEP). JAMA. 1991;265:3255-64.

15. Levy D, Larson MG, Vasan RS, Kannel WB, Ho KKL. The progression from hypertension to heart failure. J Am Coll Cardiol. 1996;275: 1557-62.

16. Stevenson WG, Stevenson LW. Prevention of sudden death in heart failure. J Cardiovasc Electrophysiol. 2001;12:112-4.

17. Kannel WB, Wilson PW, D'Agostino RB, Cobb J. Sudden coronary death in women. Am Heart J. 1998;136:205-12.

18. Kim C, Fahrenbruch CE, Cobb LA, Eisenberg MS. Out-of-hospital cardiac arrest in men and women. Circulation. 2001;104:2699-703.

19. Albert CM, Chae CU, Grodstein F, et al. Prospective study of sudden cardiac death among women in the United States. Circulation. 2003; 107:2096-101.

20. Ho K, Anderson K, Kannel W, et al. Survival after the onset of congestive heart failure in Framingham Heart Study subjects. Circulation. 1993;88:107-15.

21. Schocken DD, Arrieta MI, Leaverton PE, Ross EA. Prevalence and mortality rate of congestive heart failure in the United States. J Am Coll Cardiol. 1992;20:301-6.

22. Bourassa MG, Gurne O, Bangdiwala SI, et al. Natural history and patterns of current practice in heart failure. The Studies of Left Ventricular Dysfunction (SOLVD) Investigators. J Am Coll Cardiol. 1993;22:14A-9A.

23. Opasich C, Tavazzi L, Lucci D, et al. Comparison of one-year outcome in women versus men with chronic congestive heart failure. Am J Cardiol. 2000;86:353-7.

24. Wenger NK. Women, heart failure, and heart failure therapy. Circulation. 2002;105:1526-8.

25. Galderisi M, Anderson KM, Wilson PWF, Levy D. Echocardiographic evidence for the existence of a distinct diabetic cardiomyopathy (The Framingham Heart Study). Am J Cardiol. 1991;68:85-9.

26. Rutter MK, Parise H, Benjamin EJ, et al. Impact of glucose intolerance and insulin resistance on cardiac structure and function: sex-related differences in the Framingham Heart Study. Circulation. 2003;107: 448-54.

27. Adams KF Jr, Sueta CA, Gheorghiade M, et al. Gender differences in survival in advanced heart failure. Insights from the FIRST study. Circulation. 1999;99:1816-21.

28. Ghali JK, Pina IL, Gottlieb SS, Deedwania PC, Wikstrand JC. The M-HFSG. Metoprolol CR/XL in female patients with heart failure: analysis of the experience in Metoprolol Extended-Release Randomized Intervention Trial in Heart Failure (MERIT-HF). Circulation. 2002;105:1585-91.
29. Simon T, Mary-Krause M, Funck-Brentano C, Jaillon P. Sex differences in the prognosis of congestive heart failure: results from the Cardiac Insufficiency Bisoprolol Study (CIBIS II). Circulation. 2001; 103:375-80.

30. Fisher LD, Kennedy JW, Davis KB, et al. Association of sex, physical size, and operative mortality after coronary artery bypass in the Coronary Artery Surgery Study (CASS). J Thorac Cardiovasc Surg. 1982;84:334-41.

31. Kennedy JW, Kaiser GC, Fisher LD, et al. Clinical and angiographic predictors of operative mortality from the collaborative study in coronary artery surgery (CASS). Circulation. 1981;63:793-802.

32. Jacobs AK, Kelsey SF, Brooks MM, et al. Better outcome for women compared with men undergoing coronary revascularization: a report from the bypass angioplasty revascularization investigation (BARI). Circulation. 1998;98:1279-85.

33. Mendes LA, Davidoff R, Cupples LA, Ryan TJ, Jacobs AK. Congestive heart failure in patients with coronary artery disease: the gender paradox. Am Heart J. 1997;134:207-12.

34. Aronson D, Burger AJ. Gender-related differences in modulation of heart rate in patients with congestive heart failure. J Cardiovasc Electrophysiol. 2000;11:1071-7.

35. Guerra S, Leri A, Wang X, et al. Myocyte death in the failing human heart is gender dependent. Circ Res. 1999;85:856-66.

36. Fischer M, Baessler A, Schunkert H. Renin angiotensin system and gender differences in the cardiovascular system. Cardiovasc Res. 2002;53:672-7.

37. Crabbe DL, Dipla K, Ambati S, et al. Gender differences in postinfarction hypertrophy in end-stage failing hearts. J Am Coll Cardiol. 2003;41:300-6.

38. Harris D, Douglas PS. Enrollment of women in cardiovascular clinical trials funded by the National Heart, Lung, and Blood Institute. $N$ Engl J Med. 2000;343:475-80.

39. The CONSENSUS Trial Study Group. Effects of enalapril on mortality in severe congestive heart failure. Results of the Cooperative North Scandinavian Enalapril Survival Study (CONSENSUS). $N$ Engl J Med. 1987;316:1429-35.

40. The SOLVD Investigators. Effect of enalapril on survival in patients with reduced left ventricular ejection fractions and congestive heart failure. N Engl J Med. 1991;325:293-302.

41. The SOLVD Investigators. Effect of enalapril on mortality and the development of heart failure in asymptomatic patients with reduced left ventricular ejection fraction. N Engl J Med. 1992;327:685-91.

42. Pitt B, Segal R, Martinez FA, et al. Randomised trial of losartan versus captopril in patients over 65 with heart failure (Evaluation of Losartan in the Elderly Study, ELITE). Lancet. 1997;349:747-52.

43. Pitt B, Poole-Wilson PA, Segal R, et al. Effect of losartan compared with captopril on mortality in patients with symptomatic heart failure: randomised trial-the Losartan Heart Failure Survival Study ELITE II. Lancet. 2000;355:1582-7.

44. Hjalmarson A, Goldstein S, Fagerberg B, et al. Effects of controlledrelease metoprolol on total mortality, hospitalizations, and well-being in patients with heart failure: the Metoprolol CR/XL Randomized Intervention Trial in congestive heart failure (MERIT-HF). MERIT-HF Study Group. JAMA. 2000;283:1295-302.

45. CIBIS-II Investigators. The Cardiac Insufficiency Bisoprolol Study II: a randomised trial. Lancet. 1999;353:9-13.

46. Packer M, Coats AJ, Fowler MB, et al. Effect of carvedilol on survival in severe chronic heart failure. N Engl J Med. 2001;344:1651-8.

47. The Beta-Blocker Evaluation of Survival Trial I. A trial of the betablocker bucindolol in patients with advanced chronic heart failure. N Engl J Med. 2001;344:1659-67.

48. Cohn JN, Tognoni G, Valsartan Heart Failure Trial I. A randomized trial of the angiotensin-receptor blocker valsartan in chronic heart failure. N Engl J Med. 2001;345:1667-75.

49. Pitt B, Zannad F, Remme W, et al. The effect of spironolactone on morbidity and mortality in patients with severe heart failure. $\mathrm{N} \mathrm{Engl}$ J Med. 1999;341:709-17.

50. Pfeffer M, Braunwald E, Moye L, et al. Effect of captopril on mortality and morbidity in patients with left ventricular dysfunction after myocardial infarction. Results of the survival and ventricular enlargement trial. N Engl J Med. 1992;327:669-77. 
51. Anonymous. The TRAndolapril Cardiac Evaluation (TRACE) study: rationale, design and baseline characteristics of the screened population. The Trace Study Group. Am J Cardiol. 1994;73:44C-50C.

52. McMurray J, Ostergren J, Pfeffer M, et al. Clinical features and contemporary management of patients with low and preserved ejection fraction heart failure: baseline characteristics of patients in the Candesartan in Heart Failue-Assessment of Reduction in Mortality and morbidity (CHARM) programme. Eur Heart J. 2003;5:261-70.

53. Klein $\mathrm{H}$, Auricchio A, Reek S, Geller C. New primary prevention trials of sudden cardiac death in patients with left ventricular dysfunction: SCD-HEFT and MADIT-II. Am J Cardiol. 1999;83:91D-97D.

54. The Digitalis Investigators Group. The effect of digoxin on mortality and morbidity in patients with heart failure. N Engl J Med. 1997;336: 525-33.

55. Jessup M. The less familiar face of heart failure. J Am Coll Cardiol. 2003;41:224-6.

56. Harjai KJ, Nunez E, Stewart Humphrey J, Turgut T, Shah M, Newman J. Does gender bias exist in the medical management of heart failure? Int J Cardiol. 2000;75:65-9.
57. Keteyian SJ, Duscha BD, Brawner CA, et al. Differential effects of exercise training in men and women with chronic heart failure. $A m$ Heart J. 2003;145:912-8.

58. Duscha BD, Annex BH, Green HJ, Pippen AM, Kraus WE. Deconditioning fails to explain peripheral skeletal muscle alterations in men with chronic heart failure. J Am Coll Cardiol. 2002;39:1170-4.

59. Kostis JB, Shelton BJ, Yusuf S, et al. Tolerability of enalapril initiation by patients with left ventricular dysfunction: results of the medication challenge phase of the Studies of Left Ventricular Dysfunction. Am Heart J. 1994;128:358-64.

60. Tandon S, Hankins SR, Le Jemtel TH. Clinical profile of chronic heart failure in elderly women. Am J Geriatr Cardiol. 2002;11:318-23.

61. Adams KF Jr, Dunlap SH, Sueta CA, et al. Relation between gender, etiology and survival in patients with symptomatic heart failure. $J \mathrm{Am}$ Coll Cardiol. 1996;28:1781-8.

62. Johnstone D, Limacher M, Rousseau M, et al. Clinical characteristics of patients in studies of left ventricular dysfunction (SOLVD). Am J Cardiol. 1992;70:894-900. 